\title{
Economic impact of orthopaedic care for non-fatal gunshot wounds: analysis of a public health crisis
}

\author{
Samuel Rosas ${ }^{1}$, Chukwuweike U. Gwam ${ }^{1}$, Edgar T. Araiza ${ }^{1}$, Martin W. Roche ${ }^{2}$, Cynthia L. Emory ${ }^{1}$, \\ Eben A. Carroll ${ }^{1}$, Jason J. Halvorson ${ }^{1}$, Johannes F. Plate ${ }^{1}$ \\ ${ }^{1}$ Department of Orthopedic Surgery, Wake Forest School of Medicine, Medical Center Boulevard, Winston-Salem, NC, USA; ${ }^{2}$ Holy Cross \\ Orthopedic Institute, Fort Lauderdale, FL, USA \\ Contributions: (I) Conception and design: S Rosas; (II) Administrative support: All authors; (III) Provision of study materials or patients: S Rosas, \\ MW Roche; (IV) Collection and assembly of data: S Rosas, MW Roche; (V) Data analysis and interpretation: S Rosas, MW Roche; (VI) Manuscript \\ writing: All authors; (VII) Final approval of manuscript: All authors. \\ Correspondence to: Johannes F. Plate, MD, PhD. Department of Orthopedic Surgery, Wake Forest School of Medicine, Medical Center Boulevard, \\ Winston-Salem, NC 27101, USA. Email: joplate@gmail.com.
}

Background: The purpose of this study was to perform an epidemiological evaluation and an economic analysis of 90-day costs associated with non-fatal gunshot wounds (GSWs) to the extremities, spine and pelvis requiring orthopaedic care in the United States.

Methods: A retrospective epidemiological review of the Medicare national patient record database was conducted from 2005 to 2014. Incidence, fracture location and costs associated where evaluated. Those patients identified through International Classification of Disease (ICD)-9 revision codes and Current Procedural Terminology (CPT) Codes who sustained a fracture secondary to a GSW. Any type of surgical intervention including incision and drainage, open reduction with internal fixation, closed reduction and percutaneous fixation, etc. were identified to analyze, and evaluate costs of care as seen by charges and reimbursements to the payer. The 90-day period after initial fracture care was queried.

Results: A total of 9,765 patients required surgical orthopaedic care for GSWs. There was a total of 2,183 fractures due to GSW treated operatively in 2,201 patients. Of these, $22 \%$ were femur fractures, $18.3 \%$ were hand/wrist fractures and $16.7 \%$ were ankle/foot fractures. A majority of patients were male $(83.3 \%)$ and under 65 years of age (56.3\%). Total charges for GSW requiring orthopedic care were \$513,334,743 during the 10-year study period. Total reimbursement for these patients were $\$ 124,723,068$. Average charges per patient were highest for fracture management of the spine $\$ 431,021.33$, followed by the pelvis $\$ 392,658.45$ and later by tibia/fibula fractures $\$ 342,316.92$.

Conclusions: The 90-day direct charges and reimbursements of orthopedic care for non-fatal GSWs are of significant amounts per patient. While the number of fatal GSWs has received much attention, non-fatal GSWs have a large economic and societal impact that warrants further research and consideration by the public and policy makers.

Keywords: Gunshot wound; gunshot wounds (GSW); cost; orthopedic care; value

Submitted Jan 27, 2020. Accepted for publication Oct 12, 2020.

doi: 10.21037/atm-20-1064

View this article at: http://dx.doi.org/10.21037/atm-20-1064 


\section{Introduction}

The United States (U.S.) has the highest number of firearm-related deaths among developed countries which has been deemed a public health crisis (1-4). In 2015, the number of firearm-related deaths including suicides $(36,252)$ was similar to number of deaths from traffic accidents $(36,161)(1)$. Based on data from a publicly accessible online resource that independently tracks gun violence related events in the US (3), the incidence of gun violence increased by $15 \%$ from 51,858 incidents in 2014 to 61,552 incidents in 2017 (3). Gun violence related deaths increased by 19\% between 2014 and 2017 to a total of 15,586 deaths (3). The lifetime medical and work-loss costs of all homicides in the year 2013 were estimated by the Centers for Disease Control (CDC) at approximately 26 billion dollars (5). However, the number non-fatal gunshot wounds (GSW) increased by $26 \%$ to 31,181 injuries from 2014 to 2017 to approximately twice the number of gun violence deaths (3). While attention in the media is mostly paid to gun violence deaths, the high and increasing number of injuries from non-fatal GSWs and their societal and economic impact appear to be overlooked as a point of contention.

The treatment of GSWs is complex and often requires the inclusion of multiple medical and surgical subspecialties and major allocation of hospital resources. Specifically in orthopaedic surgery, non-fatal GSWs may require multiple procedures ranging from irrigation and debridement to operative fracture fixation or amputation due to associated major soft tissue injuries (6-8). Management for orthopedic related injuries secondary to gunshot wounds are dependent on the kinetic energy of penetrating bullet. Low velocity bullets (muzzle velocity $<350$ meters per second; i.e., most handguns) are usually treated with fracture/soft tissue stabilization and local wound care. Alternatively, high velocity bullets (muzzle velocity $>600$ meters per second; assault rifles) are treated with fracture/ soft tissue stabilization and irrigation with debridement. Nonetheless, GSW confers complex cases that not only lead to greater healthcare resource utilization, but also to loss of work productivity, decline in quality of life and long-term disability (4,9-12). Despite the aforementioned, the economic impact of non-fatal GSWs has not been previously described. This is important as healthcare related costs have continued to increase despite active measures taken by legislators and policy makers.

The purpose of this study was to perform a descriptive epidemiological study of the direct economic burden of
GSWs requiring orthopaedic care in the United States using the Medicare national database. National healthcare databases provide a unique platform and opportunity to further study and understand gun violence related events $(13-15)$. In the era of decreased funding for gun violence research from the National Institutes of Health and limited resource allocation towards gun violence by the CDC (16), it is imperative that independent groups pursue research on this topic. While the emotional and societal impact of gun violence is undisputed, the economic costs of non-fatal GSWs remains underreported, but may have a significant influence on the current debate regarding gun violence and gun control. We present the following article in accordance with the MDAR reporting checklist (available at http:// dx.doi.org/10.21037/atm-20-1064).

\section{Methods}

This study utilized a publically available database and as such did not require approval from IRB. The current study was conducted in accordance with the Declaration of Helsinki (as revised in 2013).

A retrospective epidemiological analysis of the Medicare national database was performed. The primary research question in place was: what are the recent trends in GSW related fractures to the extremities, pelvis and spine and what is their cost. The PearlDiver Server (Colorado Springs, CO) was used as a platform to access and analyze these patients. The dataset was comprised of the Medicare Standard Analytical Files (SAF) which allows for a comprehensive analysis of over 50 million lives based on records captured from January 2005 to December 2014. Patients can be tracked longitudinally and are identified through International Classification of Disease 9th revision codes (ICD) and Current Procedural Terminology (CPT) codes. Patients with an ICD-9 code of an injury related to a GSW resulting in surgical treatment were included in the study. Patients were stratified based on any orthopaedic procedures performed as described previously (17).

Anatomical regions of interest were separated into: humerus, radius/ulna, wrist/hand, femur, tibia/fibula, foot and ankle, spine and pelvis (17).

\section{Statistical analysis}

Demographic data was captured and analyzed based on annual incidences per 100,000 people, trends over time, 
length of stay and costs. Costs were depicted by charges and reimbursements related to the procedures performed on GSW patients. Both charges and reimbursements are included.

Descriptive statistics were reported as means and standard deviations (SD). Linear regressions were used to analyze trends over time (SPSS 20, IBM Corporation, Armonk, NY). A P value of 0.05 was set as the threshold for statistical significance.

Table 1 Demographic information for patients who sustained GSW between 2005 and 2014

\begin{tabular}{lc}
\hline & Data $(\%)$ \\
\hline Age distribution & 1.0 \\
Unknown & 55.3 \\
64 and under & 15.4 \\
$65-69$ & 11.7 \\
$70-74$ & 8.0 \\
$75-79$ & 5.3 \\
$80-84$ & 3.2 \\
85 and over & \\
Gender distribution & 16.5 \\
Female & 82.3 \\
Male & 1.2 \\
Unknown
\end{tabular}

\section{Results}

\section{GSW-related fractures: incidence and demographics}

This study identified 9,765 patients treated for GSWs in the Medicare database for a mean annual incidence of 3.88 (SD 3.2) per 100,000 patients without significant annual variation $(\mathrm{P}=0.923)$. There were a total of 2,183 fractures due to GSW treated operatively with an annual incidence of 1.825 per 100,000 patients (SD 0.779), without a significant annual variation $(\mathrm{P}=0.948)$.

The majority of patients sustaining GSWs were aged 64 and under $(55.3 \%)$, and men overwhelmingly suffered from these injuries relative to their female counterparts (82.3 vs. $16.5 \%$ ) (Table 1).

The annual incidence of GSW-related humerus, radius/ ulna, wrist/hand, femur, tibia/fibula, ankle/foot, pelvis, and spine fractures saw a steady increase from 2005 to 2008 (Table 2). From 2008 to 2010, there was a considerable rise in the incidence of all fractures secondary to GSWs, which steadily decreased in all fracture types from 2011 through 2014. Throughout the study period, wrist and/or hand and ankle and/or foot fractures remained the predominant fracture types.

The tendency for surgical treatment of fractures sustained secondary to GSW demonstrated a similar trend (Figure 1). From 2005 to 2008, all fracture types had an increasingly greater likelihood of being treated surgically, with a peak in 2009 and 2010, and a steady decline through 2014. Throughout this period, GSW-related wrist and/or hand, femur, and ankle and/or foot fractures were operated

Table 2 Annual incidence of fractures due to GSW (incidence per 100,000)

\begin{tabular}{lcccccccccc}
\hline Year & Humerus & Radius and/or Ulna & Wrist and/or Hand & Femur & Tibia and/or Fibula & Ankle and/or Foot & Pelvis & Spine \\
\hline 2005 & 0.153 & 0.173 & 0.382 & 0.276 & 0.228 & 0.536 & 0.086 & 0.295 \\
2006 & 0.145 & 0.195 & 0.357 & 0.245 & 0.218 & 0.449 & 0.076 & 0.330 \\
2007 & 0.195 & 0.210 & 0.512 & 0.283 & 0.214 & 0.459 & 0.065 & 0.401 \\
2008 & 0.207 & 0.249 & 0.599 & 0.319 & 0.219 & 0.542 & 0.080 & 0.353 \\
2009 & 0.322 & 0.515 & 1.140 & 0.674 & 0.531 & 1.074 & 0.267 & 0.737 \\
2010 & 0.426 & 0.560 & 1.509 & 0.848 & 0.606 & 1.175 & 0.288 & 0.917 \\
2011 & 0.196 & 0.260 & 0.561 & 0.358 & 0.297 & 0.561 & 0.109 & 0.444 \\
2012 & 0.148 & 0.181 & 0.411 & 0.348 & 0.248 & 0.526 & 0.092 & 0.293 \\
2013 & 0.150 & 0.157 & 0.378 & 0.308 & 0.201 & 0.473 & 0.088 & 0.315 \\
2014 & 0.139 & 0.139 & 0.354 & 0.307 & 0.204 & 0.416 & 0.080 & 0.307 \\
\hline
\end{tabular}




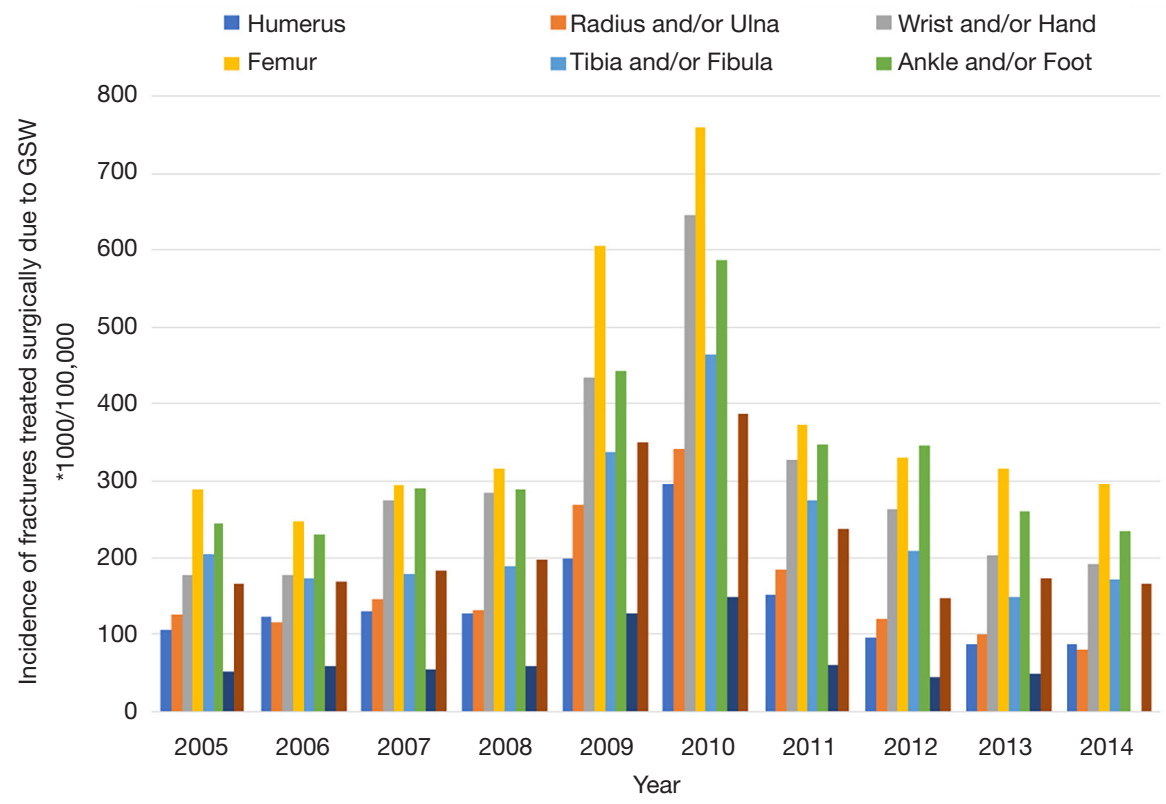

Figure 1 Incidence of GSW fractures treated surgically, stratified by anatomical location (incidence per 100,000).

Table 3 Incidence of fractures secondary to GSW, and the proportion of fractures treated surgically

\begin{tabular}{lccc}
\hline Anatomical site & $\begin{array}{c}\text { Number of } \\
\text { GSW causing } \\
\text { fractures }\end{array}$ & $\begin{array}{c}\text { Number of } \\
\text { fractures } \\
\text { treated } \\
\text { surgically }\end{array}$ & $\begin{array}{c}\text { Proportion of } \\
\text { fractures } \\
\text { treated } \\
\text { surgically }\end{array}$ \\
\hline Humerus & 322 & 168 & $52.17 \%$ \\
Radius and/or Ulna & 401 & 198 & $49.38 \%$ \\
Wrist and/or Hand & 1,099 & 399 & $36.31 \%$ \\
Femur & 603 & 481 & $79.77 \%$ \\
Tibia and/or Fibula & 464 & 283 & $60.99 \%$ \\
Ankle and/or Foot & 922 & 364 & $39.48 \%$ \\
Pelvis & 201 & 78 & $38.81 \%$ \\
Spine & 609 & 212 & $34.81 \%$ \\
\hline
\end{tabular}

on in the highest rates.

When the total number of GSW-related fractures were reported relative to the number of fractures treated surgically, femur fractures demonstrated the highest incidence of operative treatment $(79.77 \%)$, followed by tibia and/or fibula fractures (60.99\%) and humerus fractures (52.77\%) (Table 3). Spine fractures secondary to GSWs were the least likely (34.81\%) to be treated surgically.

\section{Economic burden of GSW-related fractures}

Total charges for GSW requiring orthopedic care were $\$ 513,334,743$ during the 10-year study period (Table 4). Total reimbursement for these patients was $\$ 124,723,068$. Average charges per patient were highest for fracture management of the spine $(\$ 431,021.33)$, followed by the pelvis $(\$ 392,658.45)$ and later by tibia/fibula fractures $(\$ 342,316.92)$. Patients sustaining GSW-related pelvis fractures had the greatest average length of stay (6.3 days), while those recovering from wrist and/or hand (2.6 days) and radius and/or ulna fractures (3.2 days) required the shortest hospital stay.

\section{Discussion}

The purpose of this study was to examine a national representative sample of patients undergoing orthopedic care for GSWs to illustrate the economic effects of these injuries in the US. The approximate healthcare cost for GSW fractures related injuries over the 10-year study period was approximately 0.5 billion dollars based on charges from direct care alone. Early research on gun violence in the 1980's analyzed national trends in GSWs and the costs of daily hospitalization and emotional costs (18). The study concluded at the time that the economic loss of premature death due to firearms occurred at $\$ 4$ billion 
Table 4 Average charges and reimbursements per patient, stratified per anatomic location

\begin{tabular}{|c|c|c|c|c|}
\hline Anatomic Location & $\begin{array}{c}\text { Number of fractures } \\
\text { operated on }\end{array}$ & Average charge/patient & $\begin{array}{c}\text { Average amount } \\
\text { paid/patient }\end{array}$ & $\begin{array}{c}\text { Average length of stay } \\
\text { (days) }\end{array}$ \\
\hline Humerus & 168 & $\$ 329,219.93$ & $\$ 71,214.98$ & 3.691 \\
\hline Wrist and/or Hand & 399 & $\$ 211,168.83$ & $\$ 54,256.97$ & 2.558 \\
\hline Ankle and/or Foot & 364 & $\$ 277,332.56$ & $\$ 66,167.75$ & 3.434 \\
\hline Pelvis & 78 & $\$ 392,658.45$ & $\$ 87,699.74$ & 6.304 \\
\hline Spine & 212 & $\$ 431,021.33$ & $\$ 107,098.92$ & 4.147 \\
\hline
\end{tabular}

dollars annually (18). A recent study from the CDC estimated the medical and work-loss costs of all homicides in the year 2013 at approximately 26 billion dollars (5) which is similar to the gross domestic product of El Salvador in 2017 (19). For comparison, a study evaluating surgical fixation of hip fracture with a Medicare database found that hemiarthroplasty 90-day claims payments occurred at a mean of $\$ 28,952$ 2014-adjusted dollars (20).

The incidence of GSW events to the extremities, pelvis and spine in this study ( 3.88 per 100,000 people) is slightly higher than the rate of deaths from drunk driving (3.77 per 100,000 people) based on available and representative data from the CDC (21). Furthermore, the number of gun violence related deaths reported in $2017(15,586)$ (3) is similar to number of deaths attributed to esophageal cancer $(15,690)(22)$ and the number of prescription opioid pain reliever associated deaths [excluding non-methadone synthetics (fentanyl)] in 2015 (approximately 17,000) (23). With the rising number of opioid pain medication related death in the US, an emergency declaration was issued by the President of the United States of America to delegate funding towards prevention, treatment and of opioid addiction and overdose as a public health emergency. Epidemiological studies have demonstrated that primary prevention is cost-effective and efficient for overall costsavings, thus emphasizing the likely value that new strategies with greater preventive methods may provide $(24,25)$. While the increase in gun violence related death has not increased as dramatically in recent years as opioid addiction and deaths from overdose, further funding and research into causes of gun related violence and possible preventive measures to decrease the incidence of GSW related injuries could have a similar impact as mandated seat belt use (26).
Orthopedic procedures most commonly included I\&D, ORIF and closed reduction internal fixation (intramedullary nailing) of long bones and hand fractures. This is in-line with trauma guidelines and other articles, that favor initial I\&D of fractures due to GSWs (16,27-29). Nwachukwu et al. evaluated the quality of cost utility analyses in orthopedic trauma and concluded that certain treatments such as total hip arthroplasty for femoral neck fractures, ORIF for distal radius fractures and scaphoid fractures and limb salvage for complex tibial fractures were costeffective at delivering care (30). These findings highlight the value produced by prompt high-level care provided for these complex fractures, but also allows to depict why such high expenditure takes place that may be a contributing factor to the high percentage of Gross Domestic Product (GDP) spent on healthcare in the U.S. Of note, spine fractures were the ones found to have higher costs in this cohort, even with non-operative management. This is not surprising as these patients usually require intensive care unit monitoring, multiple imaging modalities, a great deal of acute rehabilitation and multispecialty consultation $(31,32)$. Our results reveal a significant economic impact of non-fatal GSW for on orthopedic care providers. As such we suggest physician led efforts aimed at legislative policy change to minimize the incidence of non-fatal GSW. Guns shot wounds from high velocity firearms ( $>600$ meters second) confer higher morbidity and mortality rates. Accordingly, physician led policy should maybe be directed to limiting access to military grade weapons and assault rifles. Furthermore, orthopedists and hospital institutions should invest time and effort in educating their care region on the importance of gun safety. Finally, more efforts are necessary to establish physician-legislature coalitions 
in order to provide legislation with the most up-to-date information.

The findings of this study need to be interpreted in light several limitations. This was a retrospective analysis of a national database that required accurate coding by the health providers to decrease selection bias. Therefore, the findings of this study may underestimate the true incidence and true costs of non-fatal GSW treatment including orthopaedic surgical care. Patients were only included in this study if they had a 90-day follow-up in the national database, which were then labeled as nonfatal GSWs. This may have led to the inclusion of patients that succumbed to their injuries after the 90-day followup period. Based on the methodology of the study, fracture type, comminution, neurovascular involvement and/or other concomitant injuries were unable to be assessed in detail. Nonetheless, the usefulness of this methodology allows for estimation of costs with validates measurements. Charges and reimbursements associated with GSW care in the U.S where found to correlate with the 3:1 ratio of charges to reimbursements as has been done in the past (17). This demonstrates the predictability of these costs and how future projections may allow for proper budget estimation and resource allocation, if no policy changes take place that could transcend on the incidence of GSW events. No adjustments were made for inflation or regional differences as all these factors would affect equally patients nationally. Costs of lost productive time, rehabilitation and followup care were not included due to the study design, likely leading to a gross underestimation of the true costs of nonfatal GSWs. Quality of life adjusted years and/or costeffectiveness evaluations were not performed.

\section{Conclusions}

Despite the limitations of this national healthcare database driven study, there appears to be a significant economic burden of non-fatal GSW to the healthcare system that may have been underestimated and underreported.

\section{Acknowledgments}

Funding: None.

\section{Footnote}

Reporting Checklist: The authors have completed the MDAR reporting checklist. Available at http://dx.doi.org/10.21037/ atm-20-1064

Conflicts of Interest: All authors have completed the ICMJE uniform disclosure form (available at http://dx.doi. org/10.21037/atm-20-1064). Dr. Roche reports personal fees from Mako stryker, other from CMO orthosensor, other from mako- stryker, Orthosensor, other from makosurgical-stryker, other from Orthosensor, other from Smith \& Nephew, outside the submitted work; Dr. Carroll reports personal fees and other from $\mathrm{AO}$ Foundation, personal fees and other from AO North America, personal fees and other from DePuy, A Johnson \& Johnson Company, personal fees and other from Globus Medical, other from Orthopaedic Trauma Association, personal fees and other from Smith \& Nephew, personal fees and other from Synthes, outside the submitted work. Dr. Halvorson reports personal fees and other from Smith \& Nephew, outside the submitted work; Dr. Emory reports other from AAOS, other from AAOS Now, other from American Orthopaedic Association, other from Eastern Orthopaedic Association, other from Heron Therapeutics, other from Musculoskeletal Tumor Society, other from Ruth Jackson Orthopaedic Society, other from Southern Orthopaedic Association, outside the submitted work. The other authors have no conflicts of interest to declare.

Ethical Statement: The authors are accountable for all aspects of the work in ensuring that questions related to the accuracy or integrity of any part of the work are appropriately investigated and resolved. This study utilized a publically available database and as such did not require approval from IRB. The current study was conducted in accordance with the Declaration of Helsinki (as revised in 2013).

Open Access Statement: This is an Open Access article distributed in accordance with the Creative Commons Attribution-NonCommercial-NoDerivs 4.0 International License (CC BY-NC-ND 4.0), which permits the noncommercial replication and distribution of the article with the strict proviso that no changes or edits are made and the original work is properly cited (including links to both the formal publication through the relevant DOI and the license). See: https://creativecommons.org/licenses/by-nc-nd/4.0/.

\section{References}

1. Bauchner H, Rivara FP, Bonow RO, et al. Death by Gun 
Violence-A Public Health Crisis. JAMA 2017;318:1763-4.

2. Grinshteyn E, Hemenway D. Violent Death Rates: The US Compared with Other High-income OECD Countries, 2010. Am J Med 2016;129:266-73.

3. Gun Violance Archive. 2018. Available online: http://www. gunviolencearchive.org/. Accessed 3/14/2018 2018.

4. Cook A, Osler T, Hosmer D, et al. Gunshot wounds resulting in hospitalization in the United States: 20042013. Injury 2017;48:621-7.

5. Florence C, Haegerich T, Simon T, et al. Estimated Lifetime Medical and Work-Loss Costs of Emergency Department-Treated Nonfatal Injuries--United States, 2013. MMWR Morb Mortal Wkly Rep 2015;64:1078-82.

6. Karch DL, Lubell KM, Friday J, et al. Surveillance for violent deaths--National Violent Death Reporting System, 16 states, 2005. MMWR Surveill Summ 2008;57:1-45.

7. Smith ER, Shapiro G, Sarani B. The profile of wounding in civilian public mass shooting fatalities. J Trauma Acute Care Surg 2016;81:86-92.

8. Zavoski RW, Lapidus GD, Lerer TJ, et al. A populationbased study of severe firearm injury among children and youth. Pediatrics 1995;96:278-82.

9. Russo R, Fury M, Accardo S, et al. Economic and Educational Impact of Firearm-Related Injury on an Urban Trauma Center. Orthopedics 2016;39:e57-61.

10. Kizer KW, Vassar MJ, Harry RL, et al. Hospitalization charges, costs, and income for firearm-related injuries at a university trauma center. Jama 1995;273:1768-73.

11. Spitzer SA, Staudenmayer KL, Tennakoon L, et al. Costs and Financial Burden of Initial Hospitalizations for Firearm Injuries in the United States, 2006-2014. Am J Public Health 2017;107:770-4.

12. Hootman JM, Annest JL, Mercy JA, et al. National estimates of non-fatal firearm related injuries other than gunshot wounds. Inj Prev 2000;6:268-74.

13. Sabeh K, Alam M, Rosas S, et al. Cost Analysis of AllPolyethylene Compared to Metal-Backed Implants in Total Knee Arthroplasty. Surg Technol Int 2018;32:249-55.

14. Sabeh KG, Rosas S, Buller LT, et al. The Impact of Discharge Disposition on Episode-of-Care Reimbursement After Primary Total Hip Arthroplasty. J Arthroplasty 2017;32:2969-73.

15. Rosas S, Kurowicki J, Hughes M, et al. National Age and Gender-Specific Costs in Anterior Cruciate Ligament Reconstruction by A Single Nationwide Private Payer. Surg Technol Int 2017;31:285-93.

16. Behrman P, Redding CA, Raja S, et al. Society of Behavioral Medicine (SBM) position statement: restore
CDC funding for firearms and gun violence prevention research. Transl Behav Med 2018;8:958-61.

17. Blumberg TJ, DeFrancesco CJ, Miller DJ, et al. Firearmassociated Fractures in Children and Adolescents: Trends in the United States 2003-2012. J Pediatr Orthop 2018;38:e387-e392.

18. Nelson CL, Puskarich CL, Marks A. Gunshot wounds. Incidence, cost, and concepts of prevention. Clin Orthop Relat Res 1987:114-21.

19. The World Bank. GDP (current US\$). 2018. Available online: https://data.worldbank.org/indicator/NY.GDP. MKTP.CD?year_high_desc=true. Accessed 3/21/2018 2018.

20. Nichols CI, Vose JG, Nunley RM. Clinical Outcomes and 90-Day Costs Following Hemiarthroplasty or Total Hip Arthroplasty for Hip Fracture. J Arthroplasty 2017;32:S128-34.

21. Centers of Disease Control. Drunk Driving State Data and Maps. 2018. Available online: https://www.cdc.gov/ motorvehiclesafety/impaired_driving/states-data-tables. html.

22. National Cancer Institute. Cancer Stat Facts. 2018. Available online: www.cdc.gov/nchs/fastats/deaths. Accessed 3/21/2018.

23. National Institute on Drug Abuse. Overdose Deat Rates. 2018. Available online: www.drugabuse.gov/related-topics/ trends-statistics/overdose-death-rates. Accessed 3/21/2018 2018.

24. Fielding JE, Husten CG, Richland JH. Does preventive care save money? N Engl J Med 2008;358:2847; author reply 2847-8.

25. Cohen JT, Neumann PJ, Weinstein MC. Does preventive care save money? Health economics and the presidential candidates. N Engl J Med 2008;358:661-3.

26. Rosas S, Gwam CU, Emory CL, et al. Systemic Change for Value-Based Care in Orthopaedic Trauma. J Orthop Trauma 2019;33:e207-8.

27. Mackway-Jones K, Harrison M. Towards evidence based emergency medicine: best BETs from the Manchester Royal Infirmary. Management of uncomplicated soft tissue gunshot wounds. J Accid Emerg Med 2000;17:284-5.

28. Saadia R, Schein M. Debridement of gunshot wounds: semantics and surgery. World J Surg 2000;24:1146-9.

29. Bartlett CS, Helfet DL, Hausman MR, et al. Ballistics and gunshot wounds: effects on musculoskeletal tissues. J Am Acad Orthop Surg 2000;8:21-36.

30. Nwachukwu BU, Schairer WW, O'Dea E, et al. The 
Page 8 of 8

Quality of Cost-Utility Analyses in Orthopedic Trauma. Orthopedics 2015;38:e673-80.

31. Bono CM, Heary RF. Gunshot wounds to the spine. Spine

Cite this article as: Rosas S, Gwam CU, Araiza ET, Roche MW, Emory CL, Carroll EA, Halvorson JJ, Plate JF. Economic impact of orthopaedic care for non-fatal gunshot wounds: analysis of a public health crisis. Ann Transl Med 2021;9(3):210. doi: 10.21037/atm-20-1064
Rosas et al. Orthopedic costs of gunshot wounds in the US

J 2004;4:230-40.

32. Kitchel SH. Current treatment of gunshot wounds to the spine. Clin Orthop Relat Res 2003;(408):115-9. 